\title{
Numerical simulations of tsunamis generated by underwater volcanic explosions at Karymskoye lake (Kamchatka, Russia) and Kolumbo volcano (Aegean Sea, Greece)
}

\author{
M. Ulvrová ${ }^{1,2,3}$, R. Paris ${ }^{1,2,3}$, K. Kelfoun ${ }^{1,2,3}$, and P. Nomikou ${ }^{4}$ \\ ${ }^{1}$ Clermont Université, Université Blaise Pascal, Laboratoire Magmas et Volcans, BP 10448, 63000 Clermont-Ferrand, France \\ ${ }^{2}$ Laboratoire Magmas et Volcans (LMV), UMR6524, CNRS, 63038 Clermont-Ferrand, France \\ ${ }^{3}$ IRD, R 163, LMV, 63038 Clermont-Ferrand, France \\ ${ }^{4}$ Department of Geology and Geoenvironment, University of Athens, Athens, Greece
}

Correspondence to: M. Ulvrová (mulvrova@gmail.com)

Received: 23 October 2013 - Published in Nat. Hazards Earth Syst. Sci. Discuss.: 8 November 2013

Revised: 20 January 2014 - Accepted: 23 January 2014 - Published: 25 February 2014

\begin{abstract}
Increasing human activities along the coasts of the world provoke the necessity to assess tsunami hazard from different sources (earthquakes, landslides, volcanic activity). In this paper, we simulate tsunamis generated by underwater volcanic explosions from (1) a submerged vent in a shallow water lake (Karymskoye Lake, Kamchatka), and (2) from Kolumbo submarine volcano ( $7 \mathrm{~km}$ NE of Santorini, Aegean Sea, Greece). The 1996 tsunami in Karymskoye lake is a well-documented example and thus serves as a case study for validating the calculations. The numerical model reproduces realistically the tsunami run-ups measured onshore. Systematic numerical study of tsunamis generated by explosions of the Kolumbo volcano is then conducted for a wide range of energies. Results show that in case of reawakening, the Kolumbo volcano might represent a significant tsunami hazard for the northern, eastern and southern coasts of Santorini, even for small-power explosions.
\end{abstract}

\section{Introduction}

While tsunamis generated by earthquakes and landslides are very well documented, less attention has been paid to not so frequent but potentially damaging sources of tsunamis such as underwater explosions of volcanic or anthropic origin (e.g. Freundt et al., 2007; Paris et al., 2013). Underwater volcanic explosions are at the origin of around $1 \%$ of all tsunamis listed for the last four centuries (Latter, 1981) and are particularly tsunamigenic when occurring in shallow water geometries; for instance, where the depth of the crater is small compared to the crater size (or the energy of eruption). They typically generate waves of short period limiting propagation and damage in space, but wave run-up inland can be locally high, especially in narrow bays and lakes (Kranzer and Keller, 1959; Basov et al., 1981; Le Méhauté, 1971; Mirchina and Pelinovsky, 1988; Egorov, 2007). Existing tsunami warning systems are structured primarily to deal with earthquake-generated tsunamis and might be unsuited to deal with explosion-generated tsunamis. Unpredictability coupled with high population densities at the coasts lying in potentially damaged areas make the risk clearly evident (e.g. Nicaragua lakes, Indonesia, and Philippines, etc.). However, Paris et al. (2013) point out that volcanic tsunamis, including underwater explosions, are rarely included in volcanic hazard studies, even though they strongly expand the potential damage of many submerged volcanoes.

Tsunamis produced by underwater volcanic explosions were observed several times during the 20th century. For instance, the Kick'em Jenny volcano in the Caribbean Sea caused $2 \mathrm{~m}$ tsunami waves at Grenada Island in 1939 (Smith and Shepherd, 1993). Local tsunami waves generated by underwater explosions in the Krakatau caldera were described and photographed by Stehn et al. (1929). The Myojin-Sho (Japan) eruption in 1952 generated waves with amplitudes up to $1.4 \mathrm{~m}$ high at $130 \mathrm{~km}$ from the volcano (Niino, 1952; Dietz and Sheehy, 1954; Miyoshi and Akiba, 1954). Low 
amplitude tsunamis interpreted as the result of submarine explosions of Ritter Island volcano (Papua New Guinea) were reported in October 1972 and October 1974 in the Bismarck Sea (Cooke, 1981). The 1974 tsunami run-up was $0.5 \mathrm{~m}$ high in Sakar and Umboi islands, located $10 \mathrm{~km}$ from Ritter Island (Cooke, 1981; Soloviev and Kim, 1997). Numerous small tsunamis were reported and sometimes photographed during explosions of Kavachi volcano in the Solomon Islands (Johnson and Tuni, 1987). Repeated explosions at Karymskoye Lake (Kamchatka, Russia) in 1996 produced waves with run-ups up to $19 \mathrm{~m}$ on the shores of the lake, which has a diameter of $4 \mathrm{~km}$ and a mean depth of 50-60 m (Belousov et al., 2000). Older events worldwide are less documented and the precise nature of the tsunami sources is often uncertain. The 1716 tsunami in Taal Lake (Luzon, Philippines) is inferred to have been generated by underwater explosion because the eruptive centre was located offshore (Masó, 1904), but a landslide origin cannot be excluded. It is worth to note that many underwater volcanic explosions are not tsunamigenic, depending on their depth, magnitude and on watermagma interactions.

In order to assess the potential hazard of tsunami with volcanic underwater explosion source, we use numerical calculations performed by tsunami modelling package COMCOT (Liu et al., 1995a; Liu et al., 1998). Two different cases are simulated: (1) underwater explosions from a submerged vent at around $40 \mathrm{~m}$ depth in a shallow water (Karymskoye lake, Kamchatka, Russia) and (2) underwater explosion from Kolumbo submarine volcano in Aegean Sea (Greece).

The tsunami in Karymskoye Lake is taken as a case study for calibrating the code, since run-ups onshore were measured all around the lake several months after the eruption at more than 20 locations (Belousov et al., 2000). Indeed, the subaqueous explosion dating back to 1996 provides a unique opportunity to compare tsunami run-up values obtained by numerical modelling with field run-up measurements (cf. Fig. 1). Such an exercise has been done by Torsvik et al. (2010), who, however, neglected the non-linear phenomena that in the case of high velocity waves related to strong explosions play an important role. The scenario of the 1996 eruption, which lasted for 10 to $20 \mathrm{~h}$, and the impact of the tsunami on the shores of the lake are described by Belousov et al. (2000).

The model is then applied to simulations of tsunamis generated by potential future explosions of Kolumbo submarine volcano (Fig. 2), which is located $7 \mathrm{~km}$ off the north-east coast of Santorini island (Aegean Sea, Greece). Kolumbo has a diameter of $3 \mathrm{~km}$, with a summit crater $1.7 \mathrm{~km}$ across and $500 \mathrm{~m}$ deep (Nomikou et al., 2012a). The last recorded volcanic activity at Kolumbo took place in $1650 \mathrm{AD}$ and produced ash plumes that perforated the water surface, ash falls and tsunami on the coasts of the neighboring islands, and around 70 fatalities by volcanic gases in Santorini (Fouqué, 1879; Dominey-Howes et al., 2000; Nomikou et al., 2012b). The choice of Kolumbo is motivated by evidences of seis- micity beneath the volcano (Bohnhoff et al., 2006; Dimitriadis et al., 2009), the existence of an active crustal magma chamber (Dimitriadis et al., 2010), intense $\mathrm{CO}_{2}$ degassing from a hydrothermal field (Sigurdsson et al., 2006; Nomikou et al., 2013a; Kilias et al., 2013), and accumulation of acidic water in the crater (Carey et al., 2013).

\section{Physical model of underwater explosion}

Dynamics of an underwater volcanic eruption is a poorly known phenomenon. Complex interactions between dispersed pyroclasts of different sizes, gaseous bubbles and water make it hard to simulate this process dynamically.

A certain insight into the hydrodynamics of underwater explosions brings laboratory experiments by studying nuclear and chemical explosions (e.g. Le Méhauté and Wang, 1996; Kedrinskii, 2005). It has been observed that just after detonation, a cavity consisting predominantly of water vapour is formed. Subsequent expansion, rise and collapse of the spherical vapour cavity are at the origin of water disturbances generating radially propagating water waves.

Different flow characteristics produced after the discharge depend critically on the depth of the burst and its yield (i.e. the amount of energy released during the explosion). Several types of surface effects at underwater explosion comprise formation of a spectrum of jets with various features (Kedrinskii, 2005, p. 346). For a shallow detonation, a vertical jet is formed due to inertial motion of a liquid layer over the cavity followed by the second jet due to the cavity collapse upon decompression. Increasing the water depth of discharge is accompanied by the change of flow topology and development of multiple jets. Very deep explosions and/or weak yields cause only small-scale water disturbances.

While different jet flows are ejected, a development of water crater is initiated. The rim of the crater forms a dissipative leading wave. Gravitational collapse of the crater makes the water rush inward and forms the secondary bore accompanied by a number of smaller undulations. These surges expand radially while decreasing in amplitude (Le Méhauté and Wang, 1996, p. 8).

Several dynamical aspects of underwater explosions have been addressed numerically. Barras et al. (2012) study the dynamics of the high pressure and high temperature gas bubble formed upon the detonation in an infinite medium (i.e. they did not consider any interactions with water surface). They describe and model for the oscillation phenomena of the cavity during an underwater explosion.

Morrissey et al. (2010) numerically model a crater lake environment with a subaqueous eruption in the middle represented by a sudden release of superheated vapour. They reproduce the different flow dynamics observed in laboratory experiments depending on eruption pressure and additional mass of the steam. These simulations represent very well the event observed in 1996 in Karymskoye lake, although 


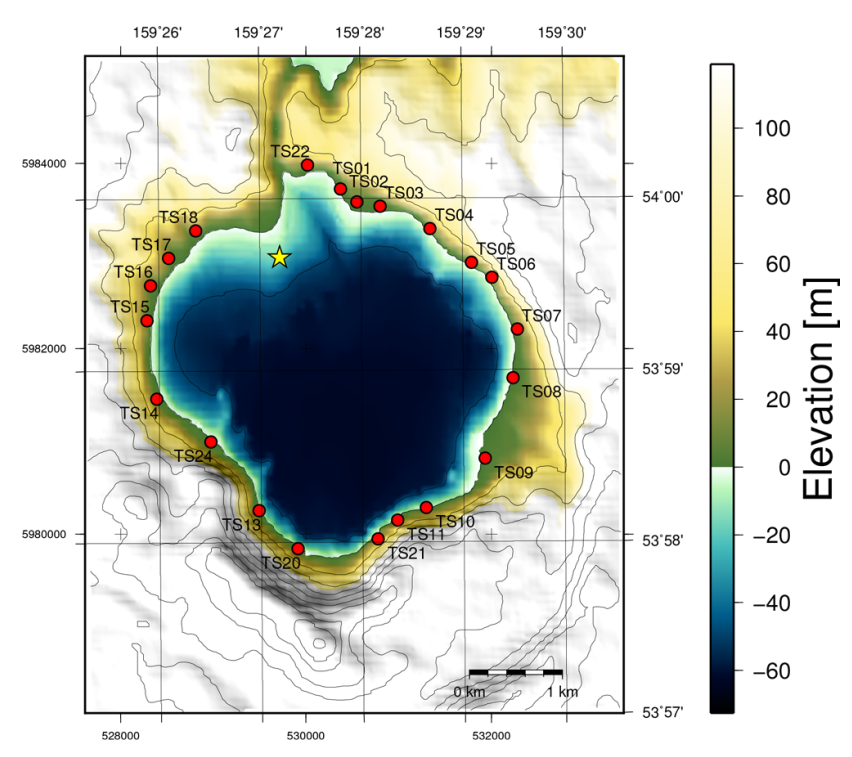

Fig. 1. Pre-eruption bathymetry (negative) and topography (positive) of the Karymskoye lake, Kamchatka, and its surrounding. Contour lines with constant contour interval $50 \mathrm{~m}$ are also depicted. Red points show locations where run-up was measured. The yellow star represents the position of the centre of the new formed crater.

they do not consider interactions of vapour with fragmented magma.

Yet, these calculations demand huge CPU times and massive parallelization since a high resolution and continuous adaptive remeshing at each time step is needed. For largescale propagation of surges, it is thus necessary to employ a semi-analytical approach. In this case, an underwater eruption is approximated by imposing a specific initial water disturbance whose propagation is modelled numerically. Although this strategy might seem too simplistic, Le Méhauté and Wang (1996) show that it reproduces satisfactorily characteristics of the wave field over a uniform depth bottom at a far distance using nonlinear and linear wave theory in comparison with artificially generated underwater explosions. The "far distance" is generally the distance where leading wave characteristics are formed but the non-linear behaviour can be ignored (i.e. three to four characteristic radii far from the detonation centre).

Le Méhauté and Wang (1996) propose several uniformly valid mathematical models for the initial water displacement $(\eta)$. Combining inverse transformation together with experimental wave records and theoretical solutions for simplified cases leads to the initial water disturbance that approximate the explosion source being a parabolic crater with a vertical steep water rim

$$
\begin{array}{ll}
\eta=\eta_{0}\left[2\left(\frac{r}{R}\right)^{2}-1\right], & \text { if } r \leq R \\
\eta=0, & \text { if } r>R,
\end{array}
$$

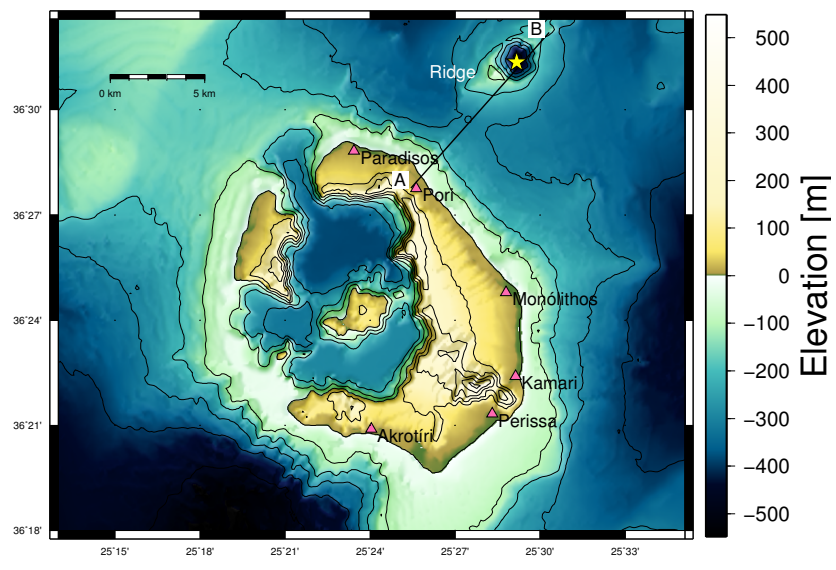

Fig. 2. Bathymetry (negative) and topography (positive) of the Santorini island, Greece, and its surrounding used for numerical simulations. Contour lines are depicted with a contour line interval $100 \mathrm{~m}$. Kolumbo volcano is represented by the yellow star. Main coastal towns are shown by pink triangles (Modified after Nomikou et al., 2013b).

that also physically corresponds to water surface displacement observed in near-surface explosion experiments (Van Dorn et al., 1968). $r$ is the distance from the explosion centre and $\eta_{0}$ is the height of the water crater rim. $R$ is the initial water crater radius where explosion takes place. We assume that it equals the mean crater radius of the volcano. Although $R$ may change in time due to landslides, erosion or sediment transport, this has only a secondary influence.

The same function for initial conditions has been also used to study tsunamis generated by asteroid impacts (e.g. Ward and Asphaug, 2000). This choice is based on a real physical resemblance with the cavity made by an impactor hitting water. In this case, the crater radius and its depth are linked to the physical properties of the impactor.

Equation (1) contains the critical parameter $\eta_{0}$ that controls the height of generated tsunami waves and its value should be linked to the explosion characteristics. There exist only purely empirical relations that estimate $\eta_{0}$ as a function of explosion energy $E(\mathrm{~J})$ released. These were derived for shallow or intermediate depth explosions. The generic scaling law is (Le Méhauté and Wang, 1996)

$\eta_{0}=c E^{0.24}$

where $c$ is a constant. According to the explosion yield, two cases are distinguished: $c=0.014$ for smaller explosions for which holds $0.076<d_{\mathrm{c}} / W^{1 / 3}<2.286\left(d_{\mathrm{c}}\right.$ is the depth of explosion, i.e. the depth of the volcano crater, in metres and $W$ the explosion yield in pounds of TNT). Larger explosions, $0<d_{\mathrm{c}} / W^{1 / 3}<0.076$, produce larger cavities and $c$ doubles, $c=0.029$. A shallower explosion thus causes a deeper water crater for the same yield.

Explosion energy $E(\mathrm{~J})$ is generally proportional to the third power of the crater diameter. Sato and Taniguchi (1997) 
give an empirical relationship

$E=3.56 \times 10^{7} R^{3}$,

where data from experimental and volcanic explosions varying over 14 orders of magnitude up to $E \sim 10^{17} \mathrm{~J}$ (corresponding to a crater radius up to $R \sim 1.5 \mathrm{~km}$ ) were used for fitting. The size of a volcanic crater represents the cumulated energy of multiple explosions (e.g Valentine et al., 2012) and might be modified by later erosion. Energy obtained from the crater radius is thus a maximum estimation used for simulating past events such as the 1996 Karymskoye Lake volcanic explosions. Simulations of future underwater explosions must be conducted for different energies which are determined from style of past eruptions. Energies considered typically range between $10^{12}$ and $10^{17} \mathrm{~J}$, corresponding approximately to a volcanic crater radius of 100 to $1500 \mathrm{~m}$.

\section{Numerical model}

In order to perform numerical simulations of volcanic explosion resulting in a tsunami wave travelling across the water, we adopt the Cornell multi-grid coupled tsunami model COMCOT (Liu et al., 1995a; Liu et al., 1998) that solves for the nonlinear shallow water equations (NSWE) (cf. Appendix A). The COMCOT numerical model has been extensively tested and validated against laboratory experiments (Liu et al., 1995b). Successful diverse applications were computed including the 1992 tsunami in Babi Island, Indonesia (Liu et al., 1995b), 1993 tsunami in Okushiri Island, Japan (Liu et al., 1995b), 1960 Chilian tsunami recorded at Hilo, Hawaii (Liu et al., 1995a) or 2004 Indian Ocean tsunami (Wang and Liu, 2006, 2007).

A tsunami wave field generated by underwater explosions depends critically on the explosion power. However, other physical parameters can change the tsunami propagation and in particular the influence of dissipative mechanisms might be important especially in shallow waters. Here, we neglect the interfacial shear stress and horizontal diffusion force, but examine the effect of bottom friction. The term describing the bottom friction is introduced in governing equations using the Manning's formula (cf. Appendix A)

$$
\frac{g n_{\mathrm{m}}^{2}}{H^{7 / 3}} \boldsymbol{F}|F|,
$$

where $g$ is the gravity, $H$ the total water depth, $\boldsymbol{F}=H \boldsymbol{v}$ the volume flux with $\boldsymbol{v}$ the horizontal velocity vector at the seafloor, and $n_{\mathrm{m}}$ the Manning coefficient. Manning coefficient should be spatially variable according to the surface roughness and in particular it should differ in between the sea bottom and populated coastal areas. However, it is often considered constant in tsunami numerical simulations and its value around $0.025 \mathrm{~m}^{-1 / 3} \mathrm{~s}$ is used in calculations. This is a value that is adapted from water engineering studies and was empirically determined for natural channels (Linsley et al., 1992, p. 314).

\section{Grid preparation}

\subsection{Karymskoye lake}

To perform simulations, topography and bathymetry data are needed. A $274 \times 334$ grid with a resolution of $21 \mathrm{~m}$ of the preeruption bathymetry and topography of Karymskoye lake and its surroundings was prepared by Torsvik et al. (2010). We further improve the quality of the grid on the shores by georeferencing and digitalising $1: 10000$ topographical maps of the lake dating 1974. The data are then interpolated on the $498 \times 488$ mesh with a resolution of $9 \mathrm{~m}$ in both horizontal directions to obtain higher precision data. The time step $\Delta t=0.01 \mathrm{~s}$ is chosen so as to satisfy the CourantFriedrichs-Lewy (CFL) condition ensuring the stability of the employed numerical scheme. The CFL condition is given by the following formula

$\Delta t \leq \frac{\Delta x}{\sqrt{g h_{\max }}}$,

where $\Delta x$ is the grid size and $h_{\max }$ is the greatest still water depth in the calculation domain.

\subsection{Kolumbo and Santorini}

To perform simulations of the tsunami generated by Kolumbo explosion registered at Santorini, we use topography and bathymetry data prepared in Nomikou et al. (2013b) (cf. Fig. 2). The swath bathymetry was obtained from several oceanographic surveys. The first data were collected in 2001, and further refined in 2006. The resulting computational grid has a spatial resolution of $50 \mathrm{~m}$. Time step size is chosen to be $\Delta t=0.15 \mathrm{~s}$ that satisfies the CFL criterion (cf. Eq. 6). Artificial tide gauges were placed offshore near areas of particular vulnerability in case of tsunami (harbours, touristic resorts, coastal towns).

\section{Results}

\subsection{Simulation of 1996 tsunami in Karymskoye lake}

The measured run-ups record the largest tsunami that was probably generated by the strongest explosion and can be matched by single event simulations (Belousov et al., 2000).

During the eruption, a new submerged crater with $200 \mathrm{~m}$ to $250 \mathrm{~m}$ in radius was formed. Using Eq. (4), energy release is estimated to lie around $5 \times 10^{14} \mathrm{~J}$. This is approximately 1600 times less than the energy released during the 1883 Krakatau eruption, where the energy equivalent to a 200 megatons atomic bomb was released (Bryant, 2008) and 5 times more than the energy released during the nuclear tests conducted on Bikini Atoll in 1946 (Le Méhauté and Wang, 1996). The initial water elevation $\eta_{0}$ is thus (cf. Eq. 3) around $50 \mathrm{~m}$. Equation (3) is approximative due to its empirical character and limited source data and should be used only as 

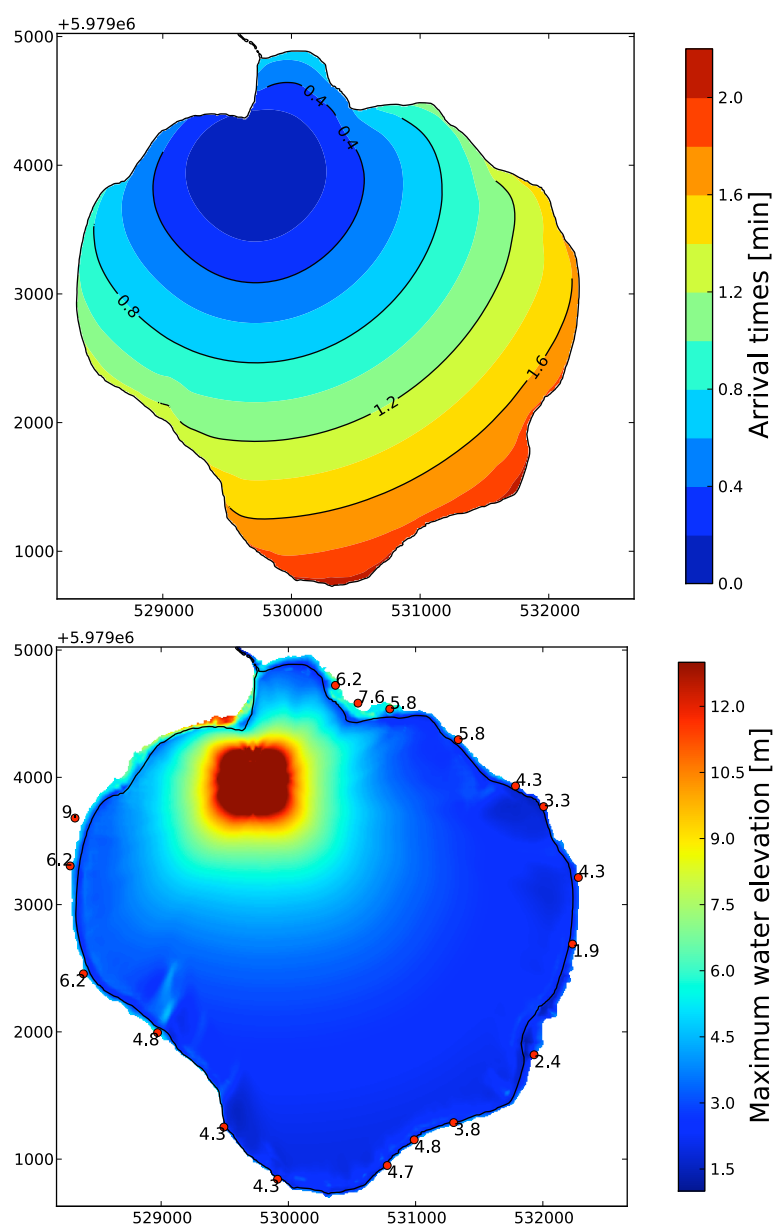

Fig. 3. Results of explosion simulation in Karymskoye lake with initial water crater rim $\eta_{0}=55 \mathrm{~m}$. (Top) First wave travel times (in minutes). (Bottom) Maximum wave amplitude. Red points indicate positions of field measured run-up with the run-up values.

a first order formula. In order to assess the suitability of our model to reproduce the field observations, we thus conduct a set of calculations by systematically varying $\eta_{0}$ around its estimated value in the range from 20 to $100 \mathrm{~m}$, corresponding to explosion energies $10^{13}-10^{16} \mathrm{~J}$.

After the explosion, waves propagate radially away from the centre of detonation with a typical velocity of $25 \mathrm{~m} \mathrm{~s}^{-1}$ reaching the southern shore in about 2 min (cf. Fig. 3 top). Highest wave amplitudes are registered in the northern part of the lake that lies closest to the impact region. A typical simulation case with $\eta_{0}=55 \mathrm{~m}$ is depicted on Fig. 3 (bottom) were field measured run-ups are also reported.

In order to quantify the match between simulated and measured values, we compute the root mean square error between observed run-up values obs ${ }_{i}$ and simulated run-ups num ${ }_{i}$

RMS error $=\sqrt{\frac{\sum_{i=1}^{N}\left(\mathrm{obs}_{i}-\mathrm{num}_{i}\right)^{2}}{N}}$.

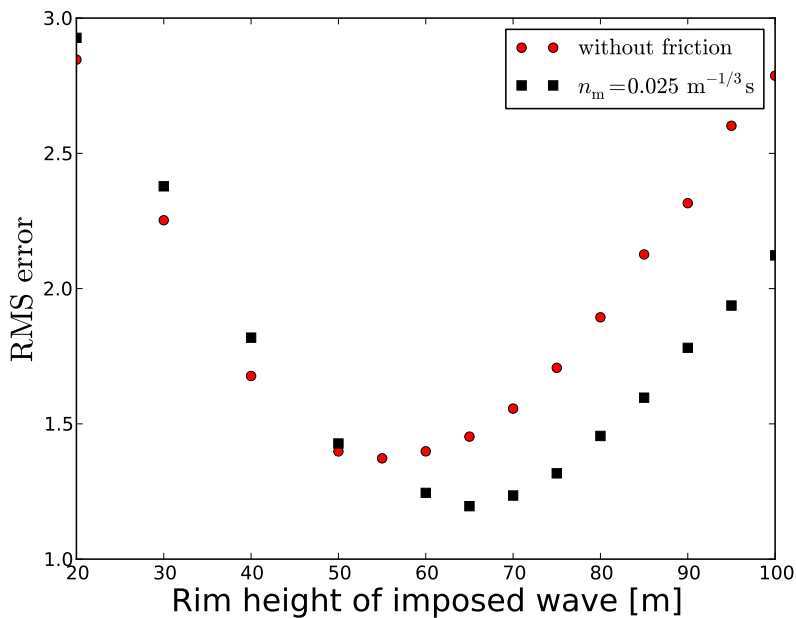

Fig. 4. Root mean square (rms) error of the difference between simulated and measured run-ups at 18 locations around the Karymskoye lake as a function of imposed amplitude of water rim $\eta_{0}$. Experiments with no friction (red circles) and Manning coefficient $n_{\mathrm{m}}=0.025 \mathrm{~m}^{-1 / 3} \mathrm{~s}$ (black squares) are reported.

From the data set we exclude three data points, TS17, TS18 and TS22 (cf. Fig. 1 for their position), as these measurements lie too close to the source where the flow experiences strong nonlinearities and more complex interactions of incoming waves with the coast are expected due to very shallow water along the wave path. Although there are other data points (north and north-east from the crater, cf. Fig. 1) that lie as close as TS17 and TS18 (e.g. TS01 or TS02) less pronounced nonlinear phenomena are expected here because waves are crossing more profound water region in this direction. Thus, they are included in the comparison exercise.

Figure 4 shows the results. We test two sets of experiments, one with no bottom friction included and one with the Manning coefficient $n_{\mathrm{m}}=0.025 \mathrm{~m}^{-1 / 3} \mathrm{~s}$. The model with zero roughness that best explains observations is the one with $\eta_{0}=55 \mathrm{~m}$ that has the RMS error of $1.37 \mathrm{~m}$, or about $27 \%$ of the observed mean. This matches extremely well the predicted height of the initial water rim of $50 \mathrm{~m}$ using the empirical laws. A detailed comparison of observed and simulated run-ups for this simulation is shown on Fig. 5. We observe a good prediction of the field data. Although overall match of measured and simulated run-ups is very good, there are some points where more important discrepancy can be observed. In particular point TS16 and a set of two points TS08 and TS09 (cf. Fig. 1 for their locations). TS16 lies in the vicinity of the Kolumbo crater and waves coming from the source cross very shallow water where the condition of a long wavelength might be not satisfied. In this case we observe underestimation of wave amplitudes. Results of the simulations for TS08 and TS09 on the south-east bank are underestimated compared to field measurements. This might be related to micro topographic features not apparent in the $9 \mathrm{~m}$ grid used for 

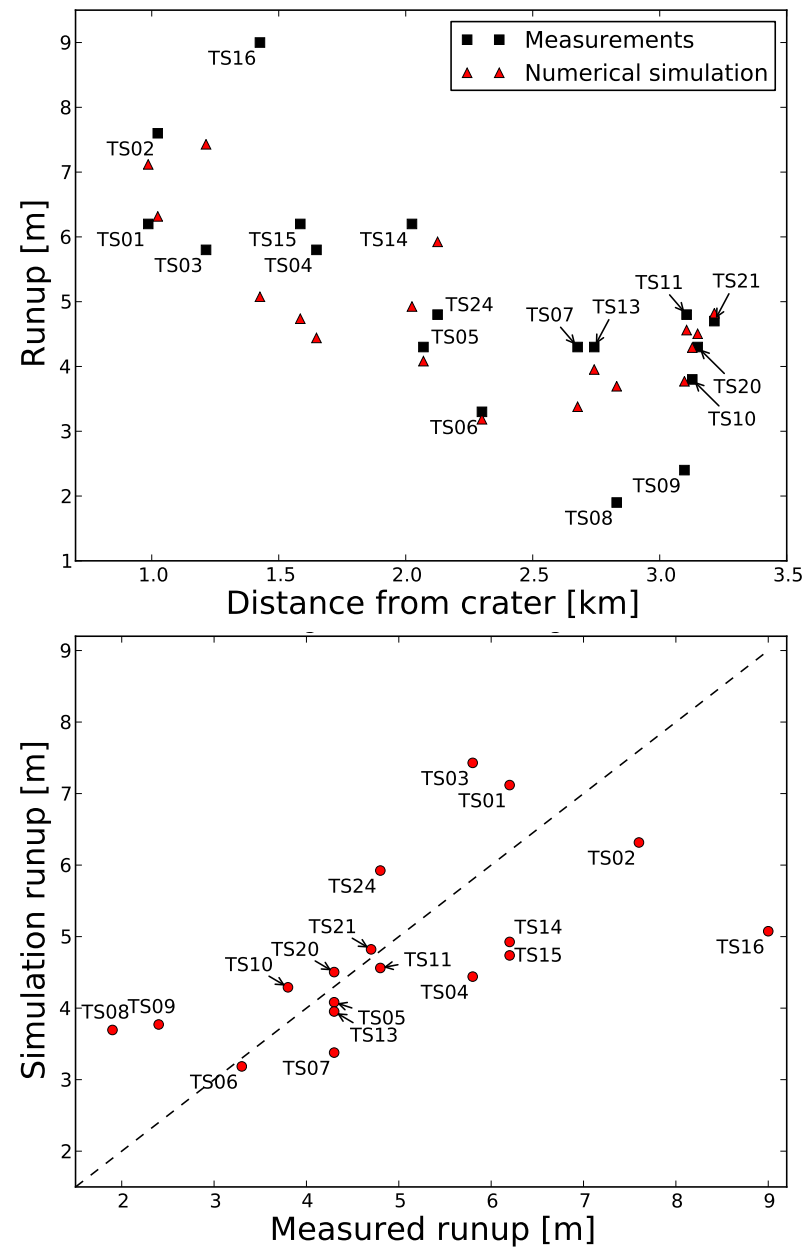

Fig. 5. Comparison of measured and simulated run-ups around the Karymskoye lake. Results are for simulation with $\eta_{0}=55 \mathrm{~m}$ and no bottom friction. (Top) Run-up as a function of distance from crater. (Bottom) Simulated run-up as a function of the measured run-up at 18 different locations. The dashed line corresponds to the simulated run-ups equal to the measured values.

calculations. Presence of terraces on this lake side limits our model that gives the best results on sites with gentle slopes (e.g. points TS10, TS11, TS21, cf. Figs. 1 and 5). Note, that no systematic underestimation or overestimation of the measured data occur. This indicates that the presented model can be used to better constrain tsunamis generated by volcanic explosions and to understand their impact in the coastal areas.

Results are only slightly modified when including dissipative processes in calculations. Although in this case we observe a better global match (i.e. rms error decreased) this difference is small. In simulations we prefer to disregard the effect of friction, as this effect is negligible by itself and is probably up to an order of magnitude smaller than other uncertainties in the system that we do not take into account such

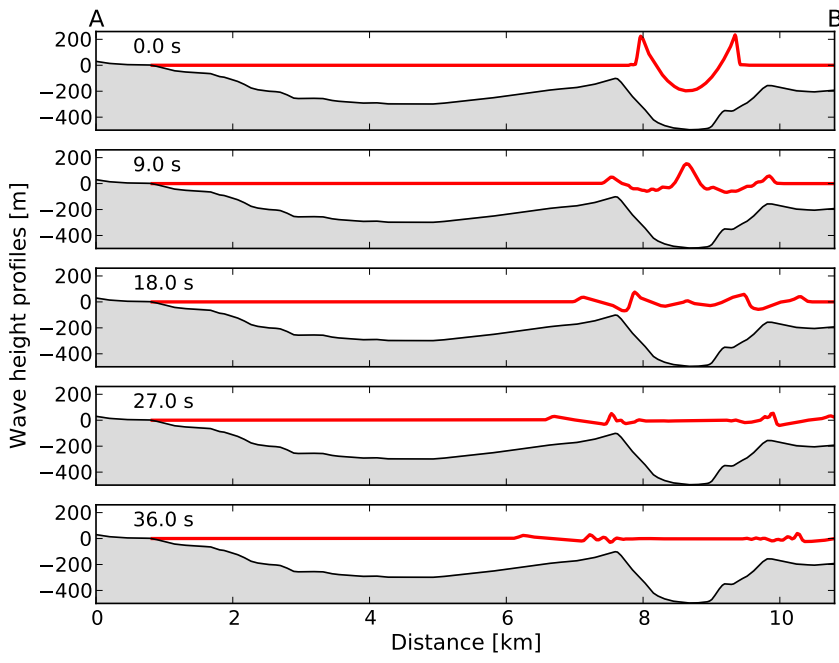

Fig. 6. A bathymetry and topography profiles (shaded areas) along AB line in Fig. 2 north-east of Santorini. Red lines depict the wave height soon after the explosion and show the formation of the positive tsunami leading wave. The explosion centre inside the Kolumbo crater lies at $9 \mathrm{~km}$ distance. Number in each figure shows time in seconds after the explosion. (Case with $\eta_{0}=250 \mathrm{~m}$.)

as interactions of surface and subsurface water with violent expulsion of magma.

\subsection{Simulations of tsunami generated by future underwater explosions of Kolumbo volcano}

The submarine Kolumbo volcanic cone, that lies about $7 \mathrm{~km}$ north-east from Santorini island, has a diameter of around $3 \mathrm{~km}$ and its crater width ranges from $1500 \mathrm{~m}$ to $1700 \mathrm{~m}$ (Nomikou et al., 2012a).

To investigate the consequences of an eventual future eruption of Kolumbo, we fix the position of the potential explosion corresponding to actual Kolumbo crater centre and systematically test different initial explosion powers. Assuming a future central eruption is justified by the morphology of the volcano (a well-developed central and no peripheral vents on the flanks of the volcano; Sigurdsson et al., 2006; Carey et al., 2013) and presence of active high-temperature fumarolic vents in the crater (Carey et al., 2013; Kilias et al., 2013). Switching the explosion from the centre to the flanks would not alter significantly our results in terms of wave arrival times and amplitudes of incoming waves. The circular source of $750 \mathrm{~m}$ radius whose middle point matches the physical centre of the Kolumbo crater is imposed with varying water rim height from $50 \mathrm{~m}$ to $350 \mathrm{~m}$ corresponding to energies from $3 \times 10^{13} \mathrm{~J}$ to $10^{17} \mathrm{~J}$ (cf. Eq. 3), following the energy range expected for future event.

The underwater explosion gives birth to waves radiating away from its centre. Collapse of the imposed initial water crater generates a positive leading wave propagating toward Santorini (cf. Fig. 6). 


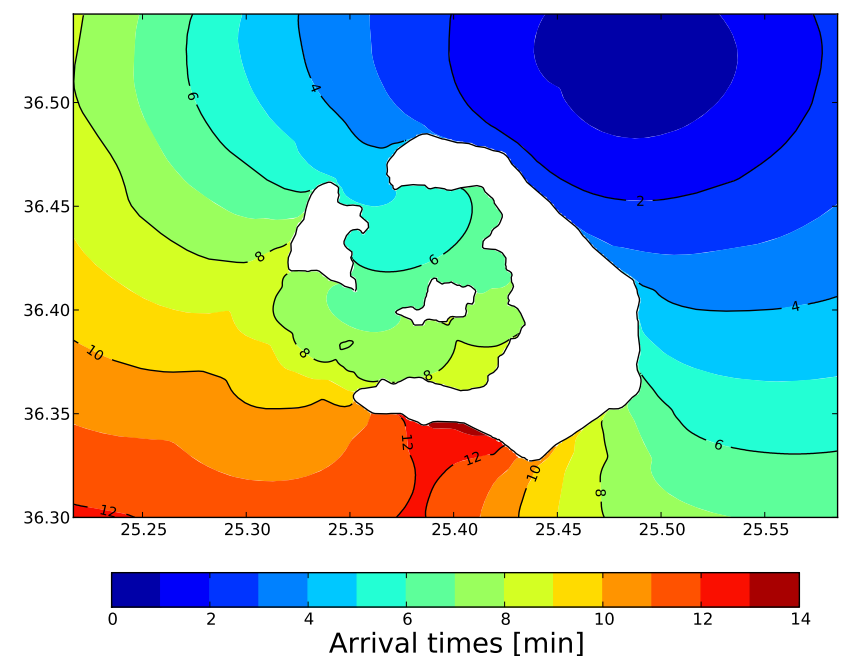

Fig. 7. First wave arrival times for Santorini island and its surroundings. Black lines are drown with an interval of $2 \mathrm{~min}$. Results are for simulation with $\eta_{0}=50 \mathrm{~m}$ and no bottom friction.

First waves reach the north-east coast of Santorini in about three minutes after the explosion (cf. Fig. 7). Northern coast is touched by the first peak in about $4 \mathrm{~min}$, the entire eastern coast in about $8 \mathrm{~min}$ and southern parts of the island (around Akrotiri) in about $14 \mathrm{~min}$ (Fig. 7, Table 1).

The corresponding waveforms registered near the six main coastal towns are shown on Fig. 8. The incoming first wave is always positive followed by a negative peak. Similar behaviour is also observed in mass flow generated tsunamis (e.g. Tinti et al., 1999; Lynett and Liu, 2002; Liu et al., 2005; Kelfoun et al., 2010; Giachetti et al., 2011) contrary to caldera collapse triggered tsunamis (e.g. Maeno et al., 2006; Maeno and Imamura, 2011; Novikova et al., 2011).

Periods are of the order of $30 \mathrm{~s}$ (Fig. 8). The larger the explosion power, the longer the wave length $\lambda$ is registered. For the weakest explosion considered in our study, $\lambda$ of the leading wave is around $1000 \mathrm{~m}$, that gives us around 20 grid points per wave length. This resolution satisfies the computational fluid dynamics requirements to obtain valid solutions.

Arrival times are weakly sensitive to the explosion power and depend strongly on the sea depth over which waves propagate, unlike the amplitudes of incoming waves. Those are given by the imposed water crater size or equivalently by the eruption energy. Figure 9 shows the maximum wave amplitudes for several $\eta_{0}$. The highest waves are recorded in the centre of explosion and decrease with increasing distance away from the source. The amplitudes are slightly enhanced in the south-west direction (direction toward Santorini) due to the presence of submarine ridge that decrease the sea floor depth (cf. Fig. 2 for bathymetry).

The highest tsunami incoming waves are registered on the northern and north-eastern coast of Santorini as these parts of the island are the most exposed to waves (Fig. 9). However,

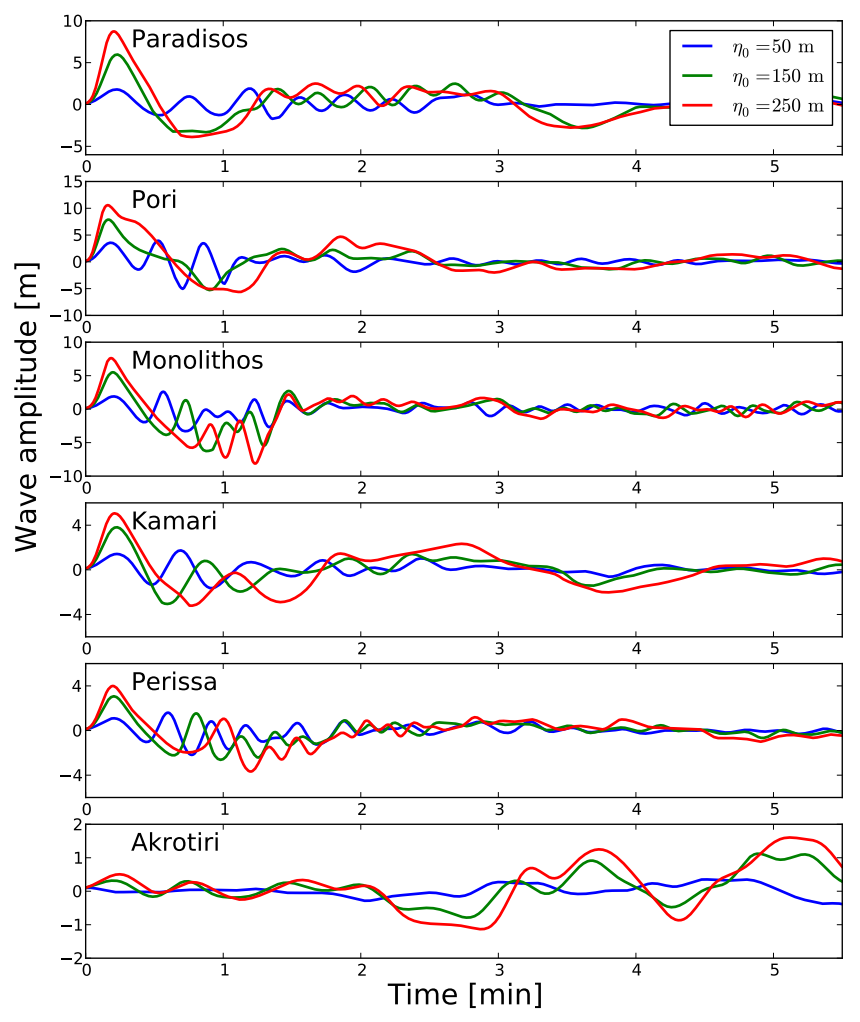

Fig. 8. Water surface displacement registered near six coastal towns along Santorini (cf. Fig. 2 for map) and for three different explosion powers. Time signals are shifted so that zero time corresponds to arrival time for a given simulation. Gauges are positioned $400 \mathrm{~m}$, $900 \mathrm{~m}, 500 \mathrm{~m}, 500 \mathrm{~m}, 800 \mathrm{~m}$ and $450 \mathrm{~m}$ off Paradisos, Pori, Monolithos, Kamari, Perissa and Akrotiri. Note, that the vertical scale is different for each location.

due to the rocky character of the northern coast, the inundation on this part is reduced. The highest tsunami impact is on the north-east and eastern coasts along Santorini as most of these areas here consist of fields with a gentle slope so the incoming waves can enter easily inland. The amplitudes of tsunami on the southern coast in the vicinity of Akrotiri are substantially reduced and the danger here is due to interference of waves coming from west and east (Figs. 8, 9 and 10). Here, the highest incoming wave is not the leading wave, but one of the trailing waves. The inner part of Santorini caldera is well protected. Arriving waves are greatly attenuated and steep high cliffs prevent large inundation (Fig. 9). Incoming waves have amplitudes inferior to $1 \mathrm{~m}$ for explosion power smaller than about $10^{16} \mathrm{~J}$. Larger explosion powers might impact harbours inside the caldera with 1-2 $\mathrm{m}$ high waves.

Figure 10 shows the maximum depth of the incoming water waves along the original coastline on the main Santorini island for several explosion powers. Maximum wave amplitude $A_{\max }$ at four main coastal towns as a function of explosion energy is represented on Fig. 11. Highest amplitudes are recorded in Pori that lies closest to the Kolumbo volcano. 
Table 1. Maximum wave amplitudes $A_{\max }$ and arrival times $t_{\mathrm{A}}$ for different explosion powers (i.e. different sizes of initial water crater rim $\left.\eta_{0}\right)$ at six different locations on Santorini. Values at gauges near the main towns (closer than about $900 \mathrm{~m}$ ) on the coast of the island are reported (cf. Fig. 2). Number in parenthesis reports the water depth at a given gauge.

\begin{tabular}{|c|c|c|c|c|c|c|c|c|c|c|c|c|}
\hline & \multicolumn{2}{|c|}{$\begin{array}{c}\text { Paradisos } \\
(-4 \mathrm{~m})\end{array}$} & \multicolumn{2}{|c|}{$\begin{array}{c}\text { Pori } \\
(-6 \mathrm{~m})\end{array}$} & \multicolumn{2}{|c|}{$\begin{array}{c}\text { Monolithos } \\
(-14 \mathrm{~m})\end{array}$} & \multicolumn{2}{|c|}{$\begin{array}{l}\text { Kamari } \\
(-4 \mathrm{~m})\end{array}$} & \multicolumn{2}{|c|}{$\begin{array}{l}\text { Perissa } \\
(-14 \mathrm{~m})\end{array}$} & \multicolumn{2}{|c|}{$\begin{array}{l}\text { Akrotiri } \\
(-3 \mathrm{~m})\end{array}$} \\
\hline & $\begin{array}{c}A_{\max } \\
(\mathrm{m})\end{array}$ & $\begin{array}{l}t_{\mathrm{A}} \\
(\mathrm{s})\end{array}$ & $\begin{array}{c}A_{\max } \\
(\mathrm{m})\end{array}$ & $\begin{array}{l}t_{\mathrm{A}} \\
(\mathrm{s})\end{array}$ & $\begin{array}{c}A_{\max } \\
(\mathrm{m})\end{array}$ & $\begin{array}{l}t_{\mathrm{A}} \\
(\mathrm{s})\end{array}$ & $\begin{array}{c}A_{\max } \\
(\mathrm{m})\end{array}$ & $\begin{array}{l}t_{\mathrm{A}} \\
(\mathrm{s})\end{array}$ & $\begin{array}{l}A_{\max } \\
(\mathrm{m})\end{array}$ & $\begin{array}{l}t_{\mathrm{A}} \\
(\mathrm{s})\end{array}$ & $\begin{array}{c}A_{\max } \\
(\mathrm{m})\end{array}$ & $\begin{array}{l}t_{\mathrm{A}} \\
(\mathrm{s})\end{array}$ \\
\hline$\eta_{0}=50 \mathrm{~m}$ & 1.9 & 195 & 4.0 & 167 & 2.6 & 261 & 1.7 & 374 & 1.6 & 516 & 0.4 & 864 \\
\hline$\eta_{0}=150 \mathrm{~m}$ & 6.0 & 188 & 7.9 & 159 & 5.5 & 254 & 3.8 & 365 & 3.1 & 505 & 1.1 & 820 \\
\hline$\eta_{0}=250 \mathrm{~m}$ & 8.7 & 183 & 10.6 & 154 & 7.6 & 249 & 5.1 & 360 & 4.0 & 498 & 1.6 & 813 \\
\hline$\eta_{0}=350 \mathrm{~m}$ & 10.6 & 180 & 12.8 & 150 & 9.0 & 246 & 5.8 & 356 & 4.5 & 493 & 1.9 & 809 \\
\hline
\end{tabular}

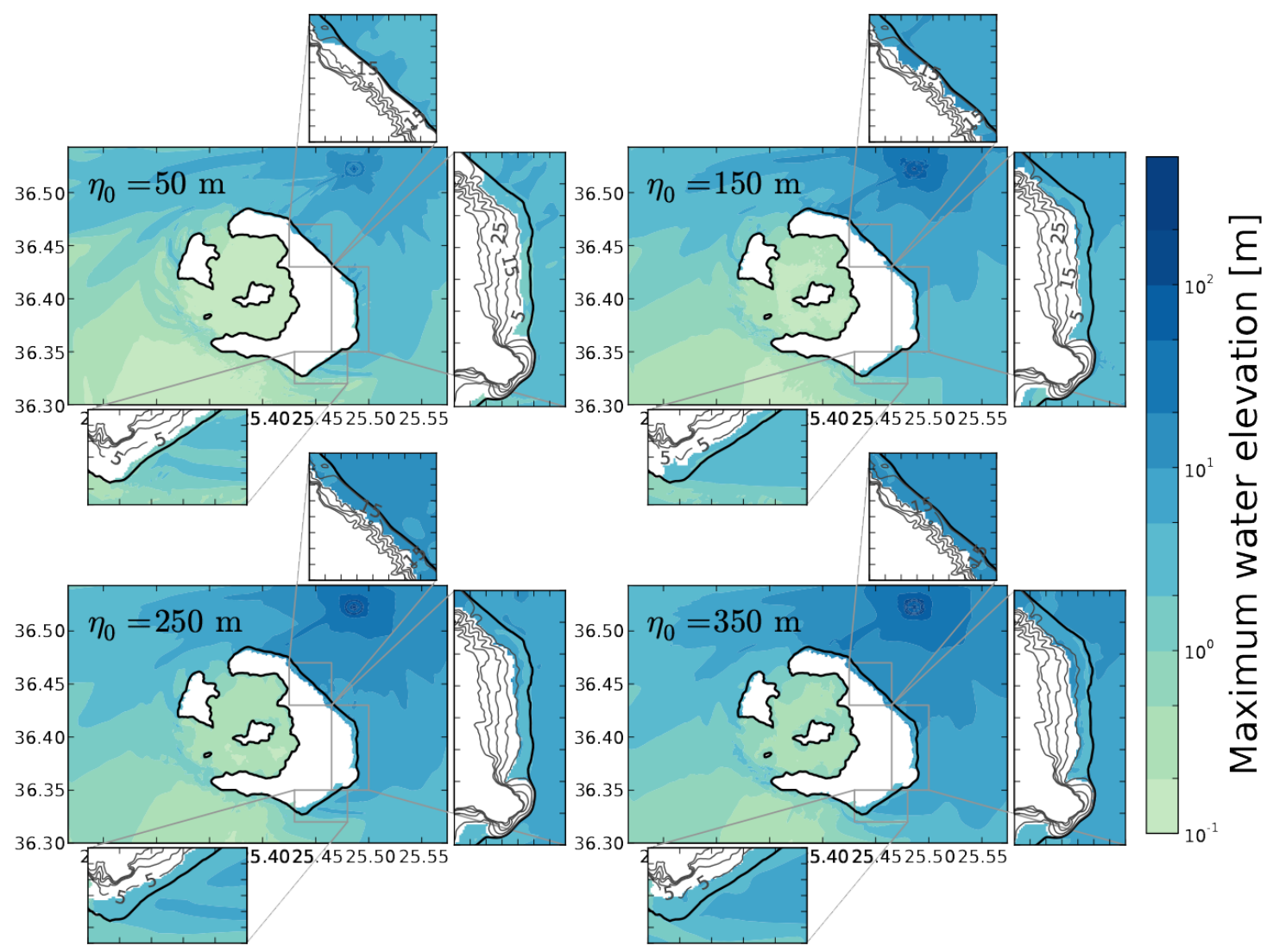

Fig. 9. Results of numerical calculations of the Kolumbo explosion generating tsunami. Maximum wave amplitudes around Santorini for several $\eta_{0}$ with zooming in the key coastal areas. Note, that the colour scale is logarithmic. Black thick solid line represents the original coastlines. Thin black lines in zooms are topography contours with $10 \mathrm{~m}$ interval starting at $5 \mathrm{~m}$. Inundation of most east coast of Santorini is visible for all four scenarios.

Increasing the explosion by approximately 3 orders of magnitude (from $10^{13} \mathrm{~J}$ to $10^{17} \mathrm{~J}$ ) more than triples $A_{\max }$ from $4 \mathrm{~m}$ to $13 \mathrm{~m}$. Waves recorded in Monólithos, Kamari and Akrotiri, respectively, vary in amplitude from approximately $2.6 \mathrm{~m}$ to $9 \mathrm{~m}, 1.7 \mathrm{~m}$ to $6 \mathrm{~m}$ and $0.4 \mathrm{~m}$ to $1.9 \mathrm{~m}$, respectively, over the explored energy power range (Fig. 11, Table 1). The predicted values might suffer partly from inaccuracy inherited from imprecise near-shore bathymetry data. However, this effect is minimised by choosing the gauge points at a certain distance from the coastal towns. At the same time all gauges lie closer than about $900 \mathrm{~m}$ from the coast.

\section{Conclusions}

We have considered underwater volcanic explosions as a tsunamigenic source and model for tsunami propagation and inundation. Since such explosions contribute only 


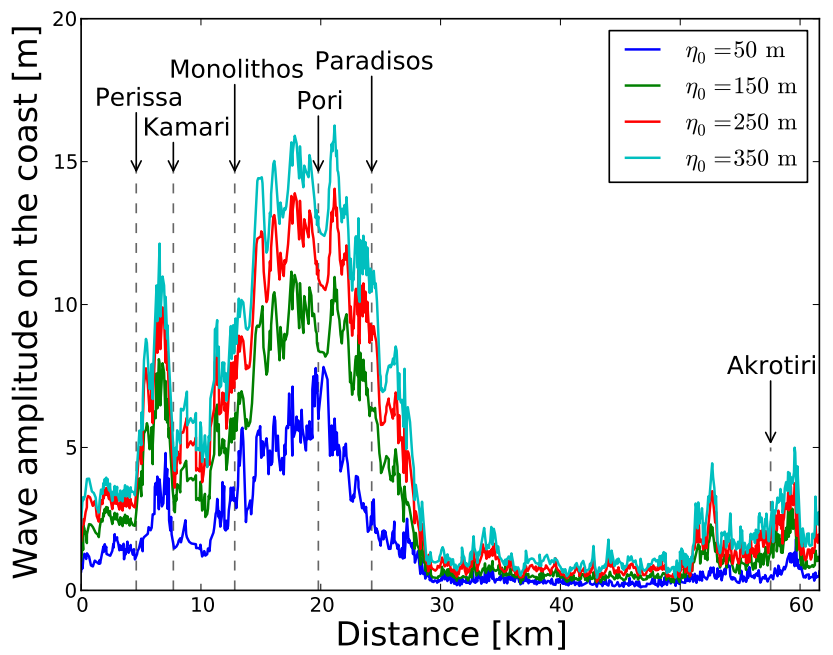

Fig. 10. Flow depth along the original coastline of the main Santorini island for several $\eta_{0}$. Distance zero corresponds to the southernmost point of the island and increases anticlockwise. Distance of the six main coastal towns is depicted by vertical arrows and dashed lines (cf. Fig. 2 for their locations).

by around $1 \%$ to all tsunami cases registered on Earth (cf. Sect. 1) they are often neglected when estimating the potential tsunami hazard although they might be particularly deadly at short distances from the volcano.

To test the model, we first investigate the 1996 tsunami generated in Karymskoye lake, Kamchatka. Shortly after the event, run-ups around the lake were measured that provides a unique data set to calibrate the numerical model (Belousov et al., 2000). We show that our modelling is capable of reproducing all the measured run-up values except the ones that are too close to the explosion centre (closer than about $1.2 \mathrm{~km})$.

Present day unrest under the Kolumbo submarine volcano (Greece, Aegean Sea), that explosively erupted for the last time in 1650, indicates the potential hazard of the next eruption. Tsunami might be generated by underwater explosions, but other sources might be considered in further investigations (e.g. flank collapse, caldera subsidence, pyroclastic flows). In order to evaluate possible impacts of Kolumbo explosion on the coast of Santorini island, we simulate tsunami generated by a range of explosion powers. The predicted waves reaching Santorini are highest on the north-east coast where registered amplitudes of incoming waves range from $4 \mathrm{~m}$ to $13 \mathrm{~m}$, respectively, for small and large explosions, respectively (varying energy from $3 \times 10^{13} \mathrm{~J}$ to $10^{17} \mathrm{~J}$ ). The east coast, where gentle slopes allow water to enter largely inland, is impacted by waves with amplitudes ranging from $2 \mathrm{~m}$ to $9 \mathrm{~m}$ for the same energy range. Southern parts of the island are well protected and incoming waves do not exceed mostly $4 \mathrm{~m}$ for the strongest explosion. The smallest waves are reg-

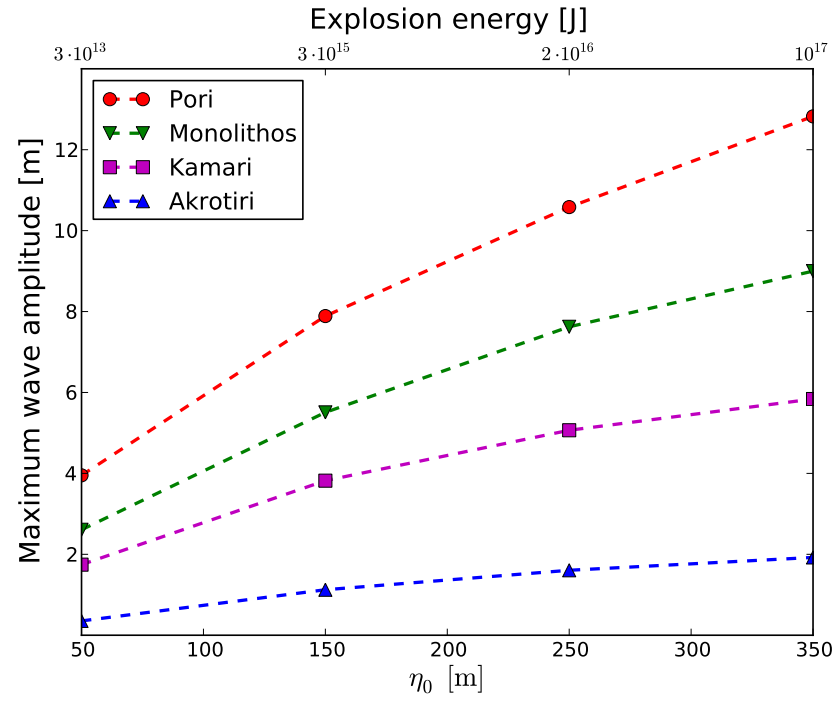

Fig. 11. Maximum wave amplitude $A_{\max }$ as a function of explosion energy registered at four different locations on the east and south coasts of Santorini (cf. Fig. 2 for their location).

istered inside the caldera with amplitudes lower than $2 \mathrm{~m}$ for all tested cases.

Future eruptions of Kolumbo volcano would impact Santorini island in terms of gas emissions, tephra fallout, earthquake and tsunami, as occurred during the 1650 eruption (Fouqué, 1879). The numerical simulations proposed herein demonstrate that underwater explosions of different powers and related tsunamis represent a significant hazard for Santorini. Existing volcanic hazard map of Santorini includes tsunami inundation in the case of the Kolumbo eruption (Fytikas et al., 1990; Vougioukalakis and Fytikas, 2005) and is based on eyewitness accounts of the 1650 tsunami. However, this document relies on the trustworthiness of these testimonies, and future eruptions might differ from the one in 1650 .

\section{Appendix A}

\section{Governing equations in COMCOT}

The standard non-linear shallow water equations are employed in COMCOT

$$
\begin{aligned}
& \frac{\partial \eta}{\partial t}+\frac{\partial P}{\partial x}+\frac{\partial Q}{\partial y}=0, \\
& \frac{\partial P}{\partial t}+\frac{\partial}{\partial x}\left(\frac{P^{2}}{H}\right)+\frac{\partial}{\partial y}\left(\frac{P Q}{H}\right)+g H \frac{\partial \eta}{\partial x}+\frac{\tau_{x}}{\rho}=0, \\
& \frac{\partial Q}{\partial t}+\frac{\partial}{\partial y}\left(\frac{Q^{2}}{H}\right)+\frac{\partial}{\partial x}\left(\frac{P Q}{H}\right)+g H \frac{\partial \eta}{\partial y}+\frac{\tau_{y}}{\rho}=0,
\end{aligned}
$$

where $\eta$ is the water free surface elevation, and $P$ and $Q$ the volume fluxes for which hold $P=H u$ and $q=H v . u$ 
and $v$ are vertically averaged velocities in $x$ and $y$ directions, respectively. $H$ is the total water depth $(H=h+\eta$ with $h$ the still water depth), $g$ the gravity acceleration and $\rho$ the water density. The last terms in Eqs. (A2) and (A3) represent bottom friction in $x$ and $y$ directions, respectively. Bottom shear stresses $\tau_{x}$ and $\tau_{y}$ are then modelled using the Manning formula

$$
\begin{aligned}
& \frac{\tau_{x}}{\rho}=\frac{g n_{\mathrm{m}}^{2}}{H^{7 / 3}} P \sqrt{P^{2}+Q^{2}}, \\
& \frac{\tau_{y}}{\rho}=\frac{g n_{\mathrm{m}}^{2}}{H^{7 / 3}} Q \sqrt{P^{2}+Q^{2}},
\end{aligned}
$$

where $n_{\mathrm{m}}$ is the Manning's roughness coefficient.

For the simplicity, only equations in the Cartesian coordinate system are given here. However, COMCOT package also solves for the governing equations in the spherical geometry with Coriolis force due to rotation of the Earth included. Cartesian coordinate system was used in all tsunami calculations in Karymskoye lake, whereas spherical coordinates were employed in the calculations of tsunamis generated by Kolumbo underwater explosion.

Acknowledgements. M. Ulvrova is grateful to Xiaoming Wang for his help with COMCOT. We thank E. Pelinovsky, D. Papanikolaou, K. I. Konstantinou and an anonymous referee for constructive comments and reviews and editor A. Costa for handling the manuscript. We also thank participants of the field trip to Santorini island in May 2013. The support for this research has been provided by FP7-ENV-2013 program ASTARTE and the Laboratory of Excellence ClerVolc. This is Laboratory of Excellence ClerVolc contribution no. 86. Multibeam data for the region around Santorini were obtained aboard R/V AEGAEO of HCMR, during 2001 (GEOWARN, IST-1999-12310) and 2006 (THERA 2006, OCE0452478). Matina Alexandri and Dionissis Ballas are gratefully acknowledged for their important and effective contribution during the cruises. This paper benefited from LATEX, GMT (Wessel and Smith, 1991) and Matplotlib (Hunter, 2007) magic.

Edited by: A. Costa

Reviewed by: E. Pelinovsky, D. Papanikolaou,

and one anonymous referee

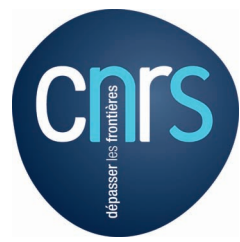

The publication of this article is financed by CNRS-INSU.

\section{References}

Barras, G., Souli, M., Aquelet, N., and Couty, N.: Numerical simulation of underwater explosions using an ALE method, the pulsating bubble phenomena, Ocean Eng., 41, 53-66, 2012.
Basov, B. I., Dorfman, A. A., Levin, B. V., and Kharlamov, A. A.: On ocean surface waves produced by underwater volcanic eruption, Vulkanologiya i Seismologiya, 1, 93-98, 1981.

Belousov, A., Voight, B., Belousova, M., and Muravyev, Y. Tsunamis generated by subaquatic volcanic explosions: unique data from 1996 eruption in Karymskoye Lake, Kamchatka, Russia, Pure Appl. Geophys., 157, 1135-1143, 2000.

Bohnhoff, M., Rische, M., Meier, T., Becker, D., Stavrakakis, G., and Harjes, H.-P.: Microseismic activity in the Hellenic Volcanic Arc, Greece, with emphasis on the seismotectonic setting of the Santorini Amorgos zone, Tectonophysics, 423, 17-33, 2006.

Bryant, E.: Tsunami: The Underrated Hazard, Springer, 2008.

Carey, S., Nomikou, P., Bell, K. C., Lilley, M., Lupton, J., Roman, C., Stathopoulou, E., Bejelou, K., and Ballard, R.: $\mathrm{CO}_{2}$ degassing from hydrothermal vents at Kolumbo submarine volcano, Greece, and the accumulation of acidic crater water, Geology, 41, 1035-1038, 2013.

Cooke, R. J. S.: Eruptive history of the volcano at Ritter Island, in: Cooke-Ravian Volume of Volcanological Papers, edited by: Johnson, R. W., vol. 10, Geol. Surv., Papua New Guinea, 115123,1981

Dietz, R. S. and Sheehy, M. J.: Transpacific detection of Myojin volcanic explosions by underwater sound, Geol. Soc. Am. Bull., 65, 941-956, 1954.

Dimitriadis, I., Karagianni, E., Panagiotopoulos, D., Papazachos, C., Hatzidimitriou, P., Bohnhoff, M., Rische, M., and Meier, T.: Seismicity and active tectonics at Coloumbo Reef (Aegean Sea, Greece): monitoring an active volcano at Santorini Volcanic Center using a temporary seismic network, Tectonophysics, 465, 136-149, 2009.

Dimitriadis, I., Papazachos, C., Panagiotopoulos, D., Hatzidimitriou, P., Bohnhoff, M., Rische, M., and Meier, T.: P and S velocity structures of the Santorini-Coloumbo volcanic system (Aegean Sea, Greece) obtained by non-linear inversion of travel times and its tectonic implications, J. Volcanol. Geoth. Res., 195, 13-30, 2010.

Dominey-Howes, D., Papadopoulos, G., and Dawson, A.: Geological and historical investigation of the $1650 \mathrm{Mt}$. Columbo (Thera Island) eruption and tsunami, Aegean Sea, Greece, Nat. Hazards, 21, 83-96, 2000.

Egorov, Y.: Tsunami wave generation by the eruption of underwater volcano, Nat. Hazards Earth Syst. Sci., 7, 65-69, doi:10.5194/nhess-7-65-2007, 2007.

Fouqué, F.: Santorin et ses éruptions, G. Masson, 1879.

Freundt, A., Strauch, W., Kutterolf, S., and Schmincke, H.-U.: Volcanogenic tsunamis in lakes: examples from Nicaragua and general implications, Pure Appl. Geophys., 164, 527-545, 2007.

Fytikas, M., Kolios, N., and Vougioukalakis, G.: Post-Minoan volcanic activity of the Santorini volcano. Volcanic hazard and risk. Forecasting possibilities, in: Therea and the Aegean World III, edited by: Hardy, D. A., Keller, J., Galanopoulos, V. P., Flemming, N. C., and Druitt, T. H., vol. 2, Proceedings of the third international congress, Santorini, Greece 3-9 September 1989, 183-198, The Thera Foundation, 1990.

Giachetti, T., Paris, R., Kelfoun, K., and Perez Torrado, F. J.: Numerical modelling of the tsunami triggered by the Guimar debris avalanche, Tenerife (Canary Islands): comparison with fieldbased data, Mar. Geol., 284, 189-202, 2011. 
Hunter, J. D.: Matplotlib: a 2D graphics environment, Comput. Sci. Eng., 9, 90-95, 2007.

Ide, S., Baltay, A., and Beroza, G. C.: Shallow dynamic overshoot and energetic deep rupture in the $2011 M_{w}$ 9.0 Tohoku-Oki earthquake, Science, 332, 1426-1429, doi:10.1126/science.1207020, 2011.

Johnson, R. W. and Tuni, D.: Kavachi, an active forearc volcano in the western Solomon Islands: reported eruptions between 1950 and 1982, in: Marine Geology, Geophysics, and Geochemistry of the Woodlark Basin: Solomon Islands, edited by: Taylor, B. J. and Exon, N. F., Earth Science Series 7, 89-112, Circum-Pacific Council for Energy and Mineral Resources, 1987.

Kedrinskii, V. K.: Hydrodynamics of Explosion, Springer, Berlin, Heidelberg, 2005.

Kelfoun, K., Giachetti, T., and Labazuy, P.: Landslide-generated tsunamis at Réunion Island, J. Geophys. Res.-Earth, 115, F04012, doi:10.1029/2009JF001381, 2010.

Kilias, S. P., Nomikou, P., Papanikolaou, D., Polymenakou, P. N., Godelitsas, A., Argyraki, A., Carey, S., Gamaletsos, P., Mertzimekis, T. J., Stathopoulou, E., Goettlicher, J., Steininger, R., Betzelou, K., Livanos, I., Christakis, C., Croff Bell, C., and Scoullos, M.: New insights into hydrothermal vent processes in the unique shallow-submarine arc-volcano, Kolumbo (Santorini), Greece, Sci. Rep., 3, 2421, doi:10.1038/srep02421, 2013.

Kranzer, H. C. and Keller, J. B.: Water waves produced by explosions, J. Appl. Phys., 30, 398-407, 1959.

Latter, J. H.: Tsunamis of volcanic origin: summary of causes, with particular reference to Krakatoa, 1883, Bull. Volcanol., 44, 467490, 1981

Le Méhauté, B. L.: Theory of explosion-generated water waves, in: Advances in Hydroscience, vol. 7, edited by: Chow, V. T., Academic Press, New York, London, 1-79, 1971.

Le Méhauté, B. L. and Wang, S.: Water Waves Generated by Underwater Explosion, Adv. Ser. Ocean Eng., World Sci., New Jersey, 1996.

Linsley, R. K., Franzini, J. B., Freyberg, D. L., and Tchobanoglous, G.: Water-Resources Engineering, 4th Edn., Series in Water Resources and Environmental Engineering, McGraw-Hill Publishing Co., 1992.

Liu, P. L.-F., Cho, Y., Yoon, S., and Seo, S.: Numerical simulations of the 1960 Chilean tsunami propagation and inundation at Hilo, Hawaii, in: Tsunami: Progress in Prediction, Disaster Prevention and Warning, edited by: Tsuchiya, Y. and Shuto, N., Advances in Natural and Technological Hazards Research, vol. 4, Springer, Netherlands, 99-115, 1995a.

Liu, P. L.-F., Cho, Y.-S., Briggs, M. J., Kanoglu, U., and Synolakis, C. E.: Runup of solitary waves on a circular island, J. Fluid Mech., 302, 259-285, 1995b.

Liu, P. L.-F., Woo, S.-B., and Cho, Y.-S.: Computer Programs for Tsunami Propagation and Inundation, Tech. rep., Cornell University, 1998.

Liu, P. L.-F., Wu, T.-R., Raichlen, F., Synolakis, C. E., and Borrero, J. C.: Runup and rundown generated by three-dimensional sliding masses, J. Fluid Mech., 536, 107-144, 2005.

Lynett, P. and Liu, P. L.-F.: A numerical study of submarinelandslide-generated waves and run-up, P. Roy. Soc. Lond. A, 458, 2885-2910, 2002.

Maeno, F. and Imamura, F.: Tsunami generation by a rapid entrance of pyroclastic flow into the sea during the 1883 Krakatau eruption, Indonesia, J. Geophys. Res.-Sol. Ea., 116, B09205, doi:10.1029/2011JB008253, 2011.

Maeno, F., Imamura, F., and Taniguchi, H.: Numerical simulation of tsunamis generated by caldera collapse during the $7.3 \mathrm{ka}$ Kikai eruption, Kyushu, Japan, Earth Planets Space, 58, 1013-1024, 2006.

Masó, M. S.: Volcanoes and seismic centers of the Philippine Archipelago, vol. 3, Department of Commerce and Labor, Bureau of the Census, 1904.

Mirchina, N. R. and Pelinovsky, E. N.: Estimation of underwater eruption energy based on tsunami wave data, Nat. Hazards, 1, 277-283, 1988.

Miyoshi, H. and Akiba, Y.: The tsunamis caused by the Myojin explosions, J. Oceanogr. Soc. Jpn., 10, 49-59, 1954.

Morrissey, M., Gisler, G., Weaver, R., and Gittings, M.: Numerical model of crater lake eruptions, Bull. Volcanol., 72, 1169-1178, 2010.

Niino, H.: Explosion of Myojin Reef: Kagaku Asahi, December, Translation available at USGS Military Geology Branch, 3-23, 1952 (in Japanese).

Nomikou, P., Carey, S., Papanikolaou, D., Croff Bell, K., Sakellariou, D., Alexandri, M., and Bejelou, K.: Submarine volcanoes of the Kolumbo volcanic zone NE of Santorini Caldera, Greece, Global Planet. Change, 90, 135-151, 2012a.

Nomikou, P., Carey, S., Bell, K., Papanikolaou, D., Bejelou, K., Cantner, K., Sakellariou, D., and Perros, I.: Tsunami hazard risk of a future volcanic eruption of Kolumbo submarine volcano, NE of Santorini Caldera, Greece, Nat. Hazards, 1-16, doi:10.1007/s11069-012-0405-0, 2012b.

Nomikou, P., Papanikolaou, D., Alexandri, M., Sakellariou, D., and Rousakis, G.: Submarine volcanoes along the Aegean volcanic arc, Tectonophysics, 597, 123-146, 2013a.

Nomikou, P., Carey, S., Croff Bell, K., Papanikolaou, D., Bejelou, K., Alexandri, M., Cantner, K., and Martin, J. F.: Morphological slope analysis in the Kolumbo submarine volcanic zone NE of Santorini Island, Z. Geomorphol., 57, 37-47, 2013b.

Novikova, T., Papadopoulos, G. A., and McCoy, F. W.: Modelling of tsunami generated by the giant Late Bronze Age eruption of Thera, South Aegean Sea, Greece, Geophys. J. Int., 186, 665680, 2011.

Paris, R., Switzer, A. A., Belousova, M., Belousov, A., Ontowirjo, B., Whelley, P. L., and Ulvrova, M.: Volcanic tsunami: a review of source mechanisms, past events and hazards in Southeast Asia (Indonesia, Philippines, Papua New Guinea), Nat. Hazards, 1-24, doi:10.1007/s11069-013-0822-8, 2013.

Sato, H. and Taniguchi, H.: Relationship between crater size and ejecta volume of recent magmatic and phreato-magmatic eruptions: implications for energy partitioning, Geophys. Res. Lett., 24, 205-208, 1997.

Sigurdsson, H., Carey, S., Alexandri, M., Vougioukalakis, G., Croff, K., Roman, C., Sakellariou, D., Anagnostou, C., Rousakis, G., Ioakim, C., Goguo, A., Ballas, D., Misaridis, T., and Nomikou, P.: Marine investigations of Greece's Santorini volcanic field, Eos Trans. AGU, 87, 337-342, 2006.

Smith, M. S. and Shepherd, J. B.: Preliminary investigations of the tsunami hazard of Kick'em Jenny submarine volcano, Nat. Hazards, 7, 257-277, 1993.

Soloviev, S. L. and Kim, K.: Catalog of tsunamis in the Pacific, 1969-1982, DIANE Publishing, 1997. 
Stehn, C., van Leeuwen, W., and Dammerman, K.: Krakatau Part I. The Geology and Volcanism of the Krakatau Group, 1929.

Tinti, S., Bortolucci, E., and Armigliato, A.: Numerical simulation of the landslide-induced tsunami of 1988 on Vulcano Island, Italy, Bull. Volcanol., 61, 121-137, 1999.

Torsvik, T., Paris, R., Didenkulova, I., Pelinovsky, E., Belousov, A., and Belousova, M.: Numerical simulation of a tsunami event during the 1996 volcanic eruption in Karymskoye lake, Kamchatka, Russia, Nat. Hazards Earth Syst. Sci., 10, 2359-2369, doi:10.5194/nhess-10-2359-2010, 2010.

Valentine, G. A., White, J. D. L., Ross, P.-S., Amin, J., Taddeucci, J., Sonder, I., and Johnson, P. J.: Experimental craters formed by single and multiple buried explosions and implications for volcanic craters with emphasis on maars, Geophys. Res. Lett., 39, L20301, doi:10.1029/2012GL053716, 2012.

Van Dorn, W. G., Le Méhauté, B., and Hwang, L.: Handbook of explosion-generated water waves: state of the art, vol. 1, Tetra Tech report, vol. 1, Tetra Tech, Inc., 1968.
Vougioukalakis, G. and Fytikas, M.: Volcanic hazards in the Aegean area, relative risk evaluation, monitoring and present state of the active volcanic centers, in: The South Aegean Active Volcanic Arc Present Knowledge and Future Perspectives Milos Conferences, edited by: Fytikas, M. and Vougioukalakis, G. E., Developments in Volcanology, vol. 7, 161-183, Elsevier, 2005.

Wang, X. and Liu, P. L.-F.: An analysis of 2004 Sumatra earthquake fault plane mechanisms and Indian Ocean tsunami, J. Hydraul. Res., 44, 147-154, 2006.

Wang, X. and Liu, P. L.-F.: Numerical simulations of the 2004 Indian Ocean tsunamis: coastal effects, J. Earthq. Tsunami, 1, 273297, 2007.

Ward, S. N. and Asphaug, E.: Asteroid impact tsunami: a probabilistic hazard assessment, Icarus, 145, 64-78, 2000.

Wessel, P. and Smith, W. H. F.: Free software helps map and display data, EOS Trans. AGU, 72, 441-446, 1991. 